Article

\title{
Modeling the Viscosity of Concentrated Nanoemulsions and Nanosuspensions
}

\section{Rajinder Pal}

Department of Chemical Engineering, University of Waterloo, Waterloo, ON N2L 3G1, Canada; rpal@uwaterloo.ca; Tel.: +1-519-888-4567 (ext. 32985)

Academic Editors: Phuoc X. Tran and Mehrdad Massoudi

Received: 20 February 2016; Accepted: 8 April 2016; Published: 12 April 2016

\begin{abstract}
The modeling of the viscous behavior of nanoemulsions and nanosuspensions is discussed. The influences of the viscosity ratio, solvation and aggregation of nanodroplets and nanoparticles on the relative viscosity of nanofluids are considered. The relative viscosity of a nanofluid is strongly affected by solvation of nanoparticles. The scaling of the relative viscosity of nanoemulsions is successfully carried out using the volume fraction of the solvated nanodroplets. Four sets of experimental relative viscosity data of nanoemulsions consisting of different diameter nanodroplets $(27.5 \mathrm{~nm}-205 \mathrm{~nm})$ all collapse on a single unique curve when the data are scaled on the basis of the volume fraction of the solvated nanodroplets. A similar scaling is achieved using six sets of experimental relative viscosity data on nanosuspensions consisting of different diameter nanoparticles $(29 \mathrm{~nm}-146 \mathrm{~nm})$. A new modified version of the Oldroyd model is proposed to describe and predict the viscosity of nanofluids. The model takes into consideration the influences of the viscosity ratio, solvation and aggregation of nanoparticles/nanodroplets. The same model is applicable to both nanoemulsions and nanosuspensions as it includes the effect of the viscosity ratio (ratio of droplet viscosity to matrix viscosity) on the relative viscosity of nanofluids. More experimental work is needed on nanoemulsions to explore the effect of the viscosity ratio, especially at low values of the viscosity ratio.
\end{abstract}

Keywords: nanofluids; nanoparticles; nanodroplets; nanosuspensions; nanoemulsions; suspensions; emulsions; viscosity

\section{Introduction}

Nanoemulsions and nanosuspensions, together referred to as nanofluids in this paper, are engineered dispersions of nanometer-sized droplets and solid-particles in a base fluid (matrix) [1]. The nanodroplets and nanoparticles of nanofluids are usually sterically-stabilized by coating the surface of the particles with surfactant or polymer molecules. Nanofluids are important from a practical point of view [1-27]. They are considered to be highly efficient heat transfer fluids with applications in power plants, motor engines, computer equipment, and many other industrial systems. In heat transfer applications, the nanoparticles are usually solid particles composed of metals, oxides, or carbides. The base fluids used are generally oil, water and ethylene glycol. The thermal conductivity, and hence the heat transfer characteristics of fluids, are greatly enhanced by incorporation of nanoparticles in the base fluid. Yang and co-workers [23-27] have recently demonstrated that nanoemulsions are equally important as nanosuspensions in many heat transfer applications. Nanofluids are also important in the formulation of paints, coatings, foods, and pharmaceuticals [2-4]. For example, a number of newly discovered drugs have poor solubility in water and consequently have low bioavailability. To improve the bioavailability of poorly soluble drugs, it is often necessary to administer the drug in the form of nanosuspensions. Due to the small size of the nanoparticles, and hence large surface area, the dissolution rate of the drug is increased significantly. 
Viscosity is one of the key thermophysical properties of nanoemulsions and nanosuspensions. Knowledge of the viscosity is required for the design, selection, and operation of the equipment involved in the formulation, handling, mixing, processing, storage, and pumping of nanoemulsions and nanosuspensions.

In this article, modeling and scaling of the viscosity of nanoemulsions and nanosuspensions is discussed taking into consideration the influences of solvation and aggregation of nanodroplets/nanoparticles. The effect of the viscosity ratio, defined as the ratio of nanodroplet viscosity to matrix viscosity, is also considered. A new modified-Oldroyd model is proposed for the viscosity of concentrated nanofluids that is applicable to both nanoemulsions and nanosuspensions. In order to validate the model, four sets of experimental data on the viscosity of nanoemulsions and six sets of experimental data on the viscosity of nanosuspensions are considered.

\section{Theoretical Background}

\subsection{Dilute Dispersions}

The constitutive equation for a dilute dispersion of identical spherical particles is given as [28,29]:

$$
\langle\overline{\bar{\sigma}}\rangle=-\langle P\rangle \overline{\bar{\delta}}+2 \eta_{m}\langle\overline{\bar{E}}\rangle+\frac{3 \varphi}{4 \pi R^{3}} \overline{\bar{S}}^{0}
$$

where $\langle\overline{\bar{\sigma}}\rangle$ is the bulk (average) stress tensor, $\langle P\rangle$ is the average pressure, $\overline{\bar{\delta}}$ is a unit tensor, $\eta_{m}$ is the matrix viscosity, $\langle\overline{\bar{E}}\rangle$ is the bulk rate of strain tensor, $\varphi$ is the volume fraction of particles, $R$ is the particle radius, and $\overline{\bar{S}}^{0}$ is the dipole strength of a single spherical particle located in an infinite matrix fluid. For a solid (rigid, non-porous) spherical particle, $\overline{\bar{S}}^{0}$ is given as:

$$
\overline{\bar{S}}^{0}=\frac{20}{3} \pi R^{3} \eta_{m} \overline{\bar{E}}_{\infty}
$$

where $\overline{\bar{E}}_{\infty}$ is the rate of strain tensor far away from the particle. For a dilute dispersion, the rate of strain tensor $\overline{\bar{E}}_{\infty}$ far away from the particles can be equated to the bulk or imposed rate of strain tensor $\langle\overline{\bar{E}}\rangle$. Hence for a dilute dispersion of solid spherical particles, the following constitutive equation can be obtained from Equations (1) and (2):

$$
\langle\overline{\bar{\sigma}}\rangle=-\langle P\rangle \overline{\bar{\delta}}+2 \eta_{m}\langle\overline{\bar{E}}\rangle+5 \eta_{m} \varphi\langle\overline{\bar{E}}\rangle
$$

To simplify the notation, the angular brackets $<>$ can be dropped from Equation (3). Thus,

$$
\overline{\bar{\sigma}}=-P \overline{\bar{\delta}}+2 \eta_{m}\left(1+\frac{5}{2} \varphi\right) \overline{\bar{E}}
$$

where $\overline{\bar{\sigma}}$ is the bulk stress tensor of the dispersion and $\overline{\bar{E}}$ is the imposed or bulk rate of strain tensor on the dispersion.

The constitutive equation for a homogeneous incompressible Newtonian fluid possessing a shear viscosity $\eta$ is given as:

$$
\overline{\bar{\sigma}}=-P \overline{\bar{\delta}}+2 \eta \overline{\bar{E}}
$$

Upon comparison of Equations (4) and (5), the viscosity of a dilute dispersion of solid spherical particles is as follows:

$$
\eta=\eta_{m}\left(1+\frac{5}{2} \varphi\right)
$$


Equation (6) is the celebrated Einstein relation [30,31] for the viscosity of a dilute suspension of spherical solid particles. The Einstein equation is generally valid for $\varphi<0.02$ [32].

The Einstein equation (Equation (6)) is restricted to dispersions of solid (rigid and non-porous) spherical particles. It is not applicable to emulsions, that is, dispersions of liquid droplets. The dipole strength of droplets $\overline{\bar{S}}^{0}$ depends on the viscosity ratio $\lambda$, defined as the ratio of droplet viscosity to matrix viscosity. Assuming deformation of droplets to be negligible, the force dipole strength $\bar{S}^{0}$ of a single droplet is given as:

$$
\overline{\bar{S}}^{o}=\frac{4}{3} \pi R^{3} \eta_{m}\left[\frac{2+5 \lambda}{1+\lambda}\right] \overline{\bar{E}}_{\infty}
$$

As noted earlier, the rate of strain tensor far away from the particles $\left(\overline{\bar{E}}_{\infty}\right)$ can be equated to the bulk or imposed rate of strain tensor $\langle\overline{\bar{E}}\rangle$ in the case of a dilute dispersion. Hence for a dilute emulsion, the rheological constitutive equation (Equation (1)) can be expressed as:

$$
\langle\overline{\bar{\sigma}}\rangle=-\langle P\rangle \overline{\bar{\delta}}+2 \eta_{m}\langle\overline{\bar{E}}\rangle+\varphi \eta_{m}\left[\frac{2+5 \lambda}{1+\lambda}\right]\langle\overline{\bar{E}}\rangle
$$

To simplify the notation, the angular brackets $\langle>$ are dropped from Equation (8) so that:

$$
\overline{\bar{\sigma}}=-P \overline{\bar{\delta}}+2 \eta_{m}\left[1+\frac{2+5 \lambda}{2(1+\lambda)} \varphi\right] \overline{\bar{E}}
$$

Comparing Equation (9) with the constitutive equation for a homogeneous incompressible Newtonian fluid possessing a shear viscosity $\eta$, that is, Equation (5), the following expression is obtained:

$$
\eta=\eta_{m}\left[1+\frac{2+5 \lambda}{2(1+\lambda)} \varphi\right]
$$

Equation (10) is the celebrated Taylor equation [33] for the viscosity of a dilute emulsion of spherical droplets. It is generally valid for $\varphi<0.02$. In the limit $\lambda \rightarrow \infty$, the Taylor equation reduces to the Einstein equation.

\subsection{Non-Dilute Dispersions}

The Einstein and Taylor viscosity equations are limited to infinitely dilute dispersions. They are developed on the basis of a single-particle mechanics. They do not account for any interaction between the droplets/particles. Many empirical and semi-empirical expressions have been published in the literature to relate the viscosity of non-dilute dispersions to the volume fraction of particles [34]. Here, we discuss the ones which appear frequently in the literature.

Saito [35] extended the Einstein theory to non-dilute suspensions of solid spherical particles by taking into account the hydrodynamic interactions between uncorrelated particles. The following equation was derived for the viscosity of non-dilute suspensions:

$$
\eta_{r}=\frac{\eta}{\eta_{m}}=1+\frac{5}{2}\left[\frac{\varphi}{1-\varphi}\right]
$$

where $\eta_{r}$ is the relative viscosity of dispersion, defined as the ratio of dispersion viscosity to matrix viscosity. Equation (11) could be re-cast as:

$$
\eta_{r}=\left[\frac{1+\frac{3}{2} \varphi}{1-\varphi}\right]
$$

This equation is expected to be valid for moderately concentrated suspensions with $\varphi$ no more than 0.20 as it does not consider the packing and jamming of particles at high concentrations. 
Batchelor and Green [36] calculated the average stress in suspensions with two-particle hydrodynamic interactions. They developed the following expression for the relative viscosity by assuming a random particle distribution and neglecting Brownian motion:

$$
\eta_{r}=\left(1+\frac{5}{2} \varphi+5.2 \varphi^{2}\right)
$$

Batchelor [37] considered the influence of Brownian motion on the average stress. Brownian motion contributes to average stress in two ways: direct contribution and indirect contribution. The direct contribution of Brownian motion comes from the stress generated in the fluid by particles moving solely under the influence of the Brownian force. The indirect contribution comes from the modification of the particle distribution function by Brownian motion. The following expression was developed by Batchelor [37] for the relative viscosity of suspension under the influence of Brownian motion at low Peclet number:

$$
\eta_{r}=\left(1+\frac{5}{2} \varphi+6.2 \varphi^{2}\right)
$$

Equations (13) and (14) are generally valid up to a particle concentration of about 0.1 to 0.15 [32].

Roscoe [38] and Brinkman [39] independently utilized the effective medium approach to develop an equation for the viscosity of concentrated suspensions of solid spherical particles. The Roscoe-Brinkman equation is given as:

$$
\eta_{r}=(1-\varphi)^{-2.5}
$$

This equation reduces to the Einstein equation in the limit of $\varphi \rightarrow 0$. The Roscoe-Brinkman equation is valid for moderately concentrated suspensions $(\varphi<0.20)$. At high concentrations of particles, the Roscoe-Brinkman equation is expected to under predict the suspension viscosity as it does not take into account the packing difficulty of particles.

Mooney [40] developed a viscosity equation for suspensions of solid spherical particles using functional analysis and taking into consideration the crowding effect of particles. The Mooney equation is given as:

$$
\eta_{r}=\exp \left(\frac{2.5 \varphi}{1-\frac{\varphi}{\varphi_{m}}}\right)
$$

where $\varphi_{m}$ is the maximum packing volume fraction of particles. The Mooney equation is valid over the $\varphi$ range of $0<\varphi<\varphi_{m}$.

According to Krieger and Dougherty [41], the Mooney equation overcorrects the influence of crowding effect on the viscosity of suspensions. They developed the following equation for the viscosity of suspensions of solid spherical particles:

$$
\eta_{r}=\left(1-\frac{\varphi}{\varphi_{m}}\right)^{-2.5 \varphi_{m}}
$$

The Krieger and Dougherty equation is quite popular in the suspension literature. It reduces to the Einstein equation in the limit $\varphi \rightarrow 0$. It is valid over the $\varphi$ range of $0<\varphi<\varphi_{m}$.

$\mathrm{Pal}$ [19] has recently proposed the following equation for the viscosity of nanofluids composed of solid nanoparticles:

$$
\eta_{r}=\left\{1-\left[1+\left(\frac{1-\varphi_{m}}{\varphi_{m}^{2}}\right) \varphi_{s}\right] \varphi_{s}\right\}^{-2.5}
$$

where $\varphi_{s}$ is the volume fraction of the solvated nanoparticles. In the limit of $\varphi_{m} \rightarrow 1$ and $\varphi_{s} \rightarrow \varphi$ (no solvation of particles), Equation (18) reduces to the Roscoe-Brinkman model, Equation (15). This equation is valid over the $\varphi$ range of $0<\varphi<\varphi_{m}$. 
The viscosity equations discussed thus far in this section are restricted to suspensions of solid (rigid and non-porous) particles. They can be applied to emulsions only under the condition of infinite viscosity ratio, that is, $\lambda \rightarrow \infty$. When $\lambda \rightarrow \infty$, the liquid droplets behave as rigid spherical particles.

Oldroyd [42] developed the following equation for the viscosity of moderately concentrated emulsions using an effective medium approach:

$$
\eta_{r}=\left[\frac{10(\lambda+1)+3 \varphi(5 \lambda+2)}{10(\lambda+1)-2 \varphi(5 \lambda+2)}\right]
$$

In the limit $\varphi \rightarrow 0$, this equation reduces to the Taylor equation (Equation (10)). Interestingly, this equation also reduces to the Saito expression (Equation (12)) in the limit $\lambda \rightarrow \infty$. Like the Saito equation, the Oldroyd model is expected to be valid for moderately concentrated emulsions and suspensions with $\varphi$ no more than 0.20 .

Using the differential effective medium approach similar to that used by Roscoe [38] and Brinkman [39], and taking into consideration the crowding effect of droplets, Pal [43] derived the following expressions for the relative viscosity of concentrated emulsions:

$$
\begin{aligned}
& \eta_{r}\left[\frac{2 \eta_{r}+5 \lambda}{2+5 \lambda}\right]^{3 / 2}=\exp \left[\frac{2.5 \varphi}{1-\left(\varphi / \varphi_{m}\right)}\right] \\
& \eta_{r}\left[\frac{2 \eta_{r}+5 \lambda}{2+5 \lambda}\right]^{3 / 2}=\left(1-\frac{\varphi}{\varphi_{m}}\right)^{-2.5 \varphi_{m}}
\end{aligned}
$$

In the limit $\lambda \rightarrow \infty$, Equation (20) reduces to the Mooney equation for the viscosity of suspensions of solid particles, that is, Equation (16) whereas Equation (21) reduces to the Krieger and Dougherty equation (Equation (17)). Equations (20) and (21) are valid over the $\varphi$ range of $0<\varphi<\varphi_{m}$. One drawback of these models is that they are not explicit in $\eta_{r}$ and hence require numerical solutions to estimate the relative viscosity of emulsion.

\section{New Viscosity Model for Concentrated Nanoemulsions and Nanosuspensions}

Among the non-dilute viscosity models for suspensions and emulsions discussed in the preceding section, the one which is applicable to both emulsions and suspensions and which is explicit in nature in that the viscosity can be calculated directly without resorting to any numerical technique, is the Oldroyd model (Equation (19)). The Oldroyd model could be re-cast as:

$$
\eta_{r}=\left[\frac{1+\frac{3}{2} \varphi\left(\frac{2+5 \lambda}{5+5 \lambda}\right)}{1-\varphi\left(\frac{2+5 \lambda}{5+5 \lambda}\right)}\right]
$$

Despite the simplicity, the Oldroyd model in its current form (Equation (22)) does a poor job in predicting the viscosity of nanoemulsions and nanosuspensions. For example, Figure 1 compares the predictions of the Oldroyd model with the experimental viscosity data on oil-in-water nanoemulsions [44] with oil-to-matrix viscosity ratio of 39. Clearly, the model severely under predicts the viscosity of nanoemulsions. 


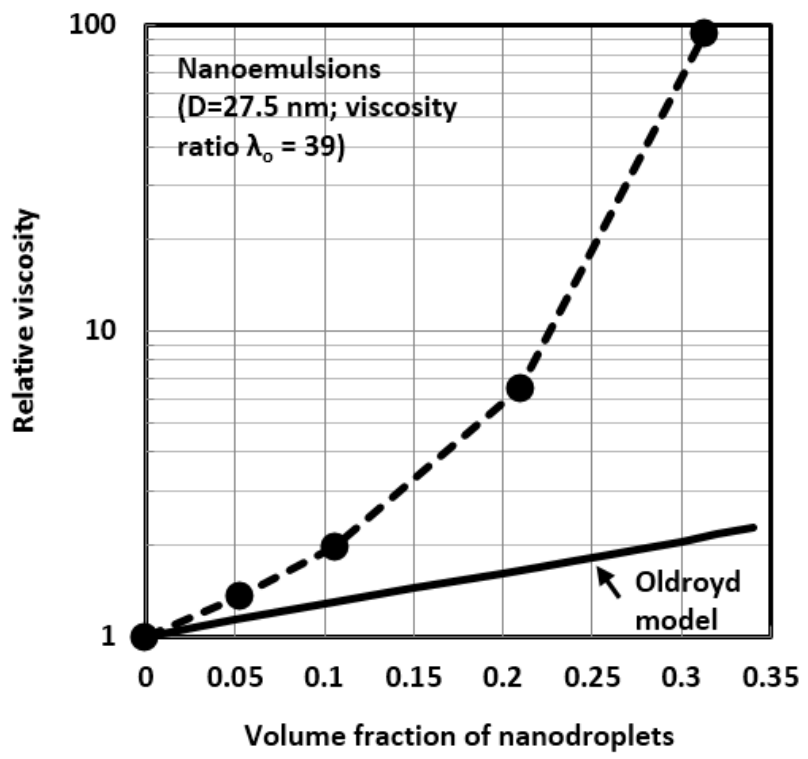

Figure 1. Comparison of experimental viscosity data for nanoemulsions [44] with the predictions of the Oldroyd model.

A similar behavior (see Figure 2) is observed for nanosuspensions in that the model severely under predicts the viscosity of $\mathrm{Al}_{2} \mathrm{O}_{3}$ nanosuspensions [14]. The reason for the poor predictability of the nanofluid viscosity by the Oldroyd model is that this model does not consider solvation and aggregation of nanoparticles/nanodroplets. Due to the small size of nanoparticles or nanodroplets, the influence of solvation films present on the surfaces of the particles could not be neglected. It is a well-known fact that lyophilic surfaces are solvated [45], that is, they are coated with thin films of the matrix fluid. Due to the strong attractive interactions between the dispersion medium (matrix) molecules and the particle surfaces, the solvation films become a part of the particles and the particles behave as swollen particles.

The volume fraction of the solvated or swollen particles/droplets is expected to be significantly larger than the actual volume fraction of particles, as expected from the following relation [46]:

$$
\varphi_{s}=\varphi\left[1+\frac{\delta}{R}\right]^{3}
$$

where $\varphi_{s}$ is the volume fraction of solvated particles/droplets, $\varphi$ is the actual volume of particles, $\delta$ is the thickness of the solvated layer, and $R$ is the radius of the particle. With the decrease in the particle radius $R$, keeping the solvation thickness $\delta$ and the actual volume fraction $\varphi$ constant, the volume fraction of the solvated particles increases. Thus the effect of the solvation layers cannot be neglected in dispersions with nanometer-sized particles and droplets. It should be noted that the thickness of the solvation layer also depends on the presence of surfactant and/or polymer molecules at the surface of the particles. The other phenomenon, which is not considered in the Oldroyd model but plays an important role in concentrated dispersions of nanometer-sized particles and droplets is the clustering/aggregation of particles [47,48]. The nanoparticles come in contact with each other due to Brownian motion and form aggregates. At low concentration of nanoparticles, the aggregates mainly consist of doublets. With further increase in nanoparticle concentration, the size of the aggregates tends to grow progressively from doublets to triplets, from triplets to quartets, from quartets to quintets, and so on. A significant amount of the matrix fluid is immobilized when aggregates are formed. Due to immobilization of the matrix fluid within the aggregates, the effective volume fraction of dispersed-phase is much higher than the volume fraction of solvated nanoparticles alone without aggregation. 


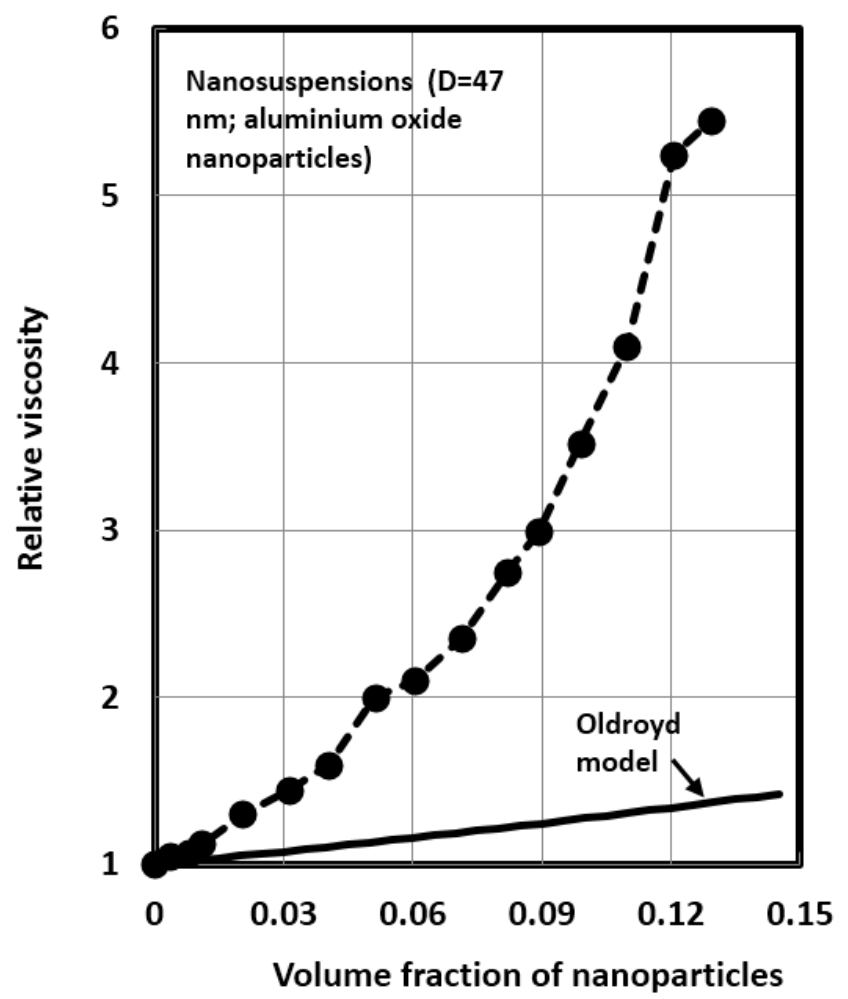

Figure 2. Comparison of experimental viscosity data for nanosuspensions [14] with the predictions of the Oldroyd model.

In order to take into account the solvation and aggregation of nanoparticles/nanodroplets, an effective volume fraction of the dispersed-phase $\left(\varphi_{e f f}\right)$ is defined as:

$$
\varphi_{e f f}=k \varphi_{s}=k k_{s} \varphi
$$

where $\varphi_{s}$ is the volume fraction of the solvated nanoparticles, $\varphi$ is the actual volume fraction of the un-solvated particles, $k$ is the aggregation coefficient defined as the ratio of $\varphi_{e f f}$ to $\varphi_{s}$, and $k_{s}$ is the solvation coefficient defined as the ratio of $\varphi_{s}$ to $\varphi$. It is this effective volume fraction of nanoparticles/nanodroplets that is incorporated into the Oldroyd model. Thus the following modified form of the Oldroyd model is proposed for the viscosity of nanosuspensions and nanoemulsions:

$$
\eta_{r}=\left[\frac{1+\frac{3}{2} \varphi_{e f f}\left(\frac{2+5 \lambda}{5+5 \lambda}\right)}{1-\varphi_{e f f}\left(\frac{2+5 \lambda}{5+5 \lambda}\right)}\right]
$$

where $\varphi_{\text {eff }}$ is given by Equation (24).

It should be noted that nanofluids generally exhibit non-Newtonian shear-thinning behaviour [19] due to competition between hydrodynamic and Brownian forces. The Brownian force tends to randomize the position of the particles resulting in clustering of particles whereas the hydrodynamic force tends to destroy the clusters resulting in ordering of particles into layers. Consequently the relative viscosity depends on the shear rate. The proposed model, Equation (25), is restricted to low shear rates (low Peclet numbers). For nanoemulsions, the capillary number is also assumed to be small.

\section{Estimation of the Solvation and Aggregation Coefficients}

The solvation coefficient $k_{s}$ can be determined from the viscosity data of a nanofluid (nanosuspension or nanoemulsion) measured in the low concentration range of nanoparticles. At low 
concentrations of nanoparticles/nanodroplets, the following modified form of the Taylor equation could be applied:

$$
\eta_{r}=1+\left(\frac{2+5 \lambda}{2+2 \lambda}\right) \varphi_{s}=1+\left(\frac{2+5 \lambda}{2+2 \lambda}\right)\left(k_{s} \varphi\right)
$$

The intrinsic viscosity [ $\eta]$ of a nanofluid is defined as:

$$
[\eta]=\operatorname{Lim}_{\varphi \rightarrow 0}\left(\frac{\eta_{r}-1}{\varphi}\right)
$$

From Equations (26) and (27), it follows that the intrinsic viscosity of a nanofluid is given as:

$$
[\eta]=\left(\frac{2+5 \lambda}{2+2 \lambda}\right) k_{s}=\left(\frac{2+5 \lambda}{2+2 \lambda}\right)\left(1+\frac{\delta}{R}\right)^{3}
$$

Thus the solvation coefficient $k_{s}$, and hence $\delta / R$, can be determined from the knowledge of the intrinsic viscosity $[\eta]$ of a nanofluid and the viscosity ratio $\lambda$. The intrinsic viscosity of a nanofluid can be determined from either the slope of $\eta_{r}$ versus $\varphi$ plot as $\varphi \rightarrow 0$ or from the slope of $1 / \eta_{r}$ versus $\varphi$ plot as $\varphi \rightarrow 0$. Note that the modified Taylor equation (Equation (26)) could be re-written as:

$$
\frac{1}{\eta_{r}}=\frac{1}{1+[\eta] \varphi}=(1+[\eta] \varphi)^{-1}=1-[\eta] \varphi+\ldots \ldots .
$$

Thus, the slope of $1 / \eta_{r}$ versus $\varphi$ data in the limit of $\varphi \rightarrow 0$ is $-[\eta]$.

As a first approximation, the viscosity ratio $\lambda$ for nanoemulsions was taken to be the ratio of un-solvated droplet viscosity to matrix viscosity to estimate $\delta / R$ from Equation (28). Strictly speaking, $\lambda$ is the ratio of effective viscosity of composite droplet (core + solvation layer) to matrix viscosity. The calculation of $\lambda$ was therefore refined as follows using the well-known Voigt rule of mixtures [28] for the effective viscosity of the composite droplets:

$$
\lambda=\lambda_{o}+\varphi_{S L}\left(1-\lambda_{o}\right)
$$

where $\lambda_{o}$ is the ratio of core viscosity (un-solvated droplet viscosity) to matrix viscosity, and $\varphi_{S L}$ is the volume fraction of solvated layer in the composite droplet given as:

$$
\varphi_{S L}=1-(1+\delta / R)^{-3}
$$

From Equations (28), (30), and (31), it readily follows that:

$$
[\eta]=\frac{2+5 \lambda_{o}+5\left(1-\lambda_{o}\right)\left(1-\left(1+\frac{\delta}{R}\right)^{-3}\right)}{2+2 \lambda_{o}+2\left(1-\lambda_{o}\right)\left(1-\left(1+\frac{\delta}{R}\right)^{-3}\right)}\left(1+\frac{\delta}{R}\right)^{3}
$$

In this equation, the only unknown is the $\delta / R$ as $[\eta]$ is known through measurements. Thus the value of the relative thickness of the solvation layer, $\delta / R$, could be obtained directly from Equation (32). Alternatively, one can use an iterative procedure to estimate $\delta / R$ as follows: Estimate $\delta / R$ from Equation (28) using $\lambda=\lambda_{o}$, calculate $\varphi_{S L}$ from Equation (31), calculate improved values of $\lambda$ and $\delta / R$ from Equations (30) and (28), respectively. Repeat the calculations until convergence.

The aggregation coefficient $k$ is expected to increase with the increase in the concentration of the solvated nanoparticles/nanodroplets due to the growth of the aggregates. Thus:

$$
k=k\left(\varphi_{s}\right)
$$


We have explored different forms of the above relationship between $k$ and $\varphi_{s}$ and have determined the form which best represents the experimental data on the viscosity of nanosuspensions and nanoemulsions. The relationship between $k$ and $\varphi_{s}$ is required to fulfil the following condition: when $\varphi_{s} \rightarrow \varphi_{m}, \varphi_{e f f}=1$ and consequently $k=1 / \varphi_{m}$ where $\varphi_{m}$ is the maximum packing volume fraction of nanoparticles. The various forms of Equation (33) explored in this work are as follows:

$$
\begin{gathered}
k=\frac{\varphi_{e f f}}{\varphi_{s}}=\frac{1}{\varphi_{m}} \\
k=\frac{\varphi_{e f f}}{\varphi_{s}}=1+\left[\frac{1-\varphi_{m}}{\varphi_{m}^{2}}\right] \varphi_{s} \\
k=\frac{\varphi_{e f f}}{\varphi_{s}}=1+\left(\frac{1-\varphi_{m}}{\varphi_{m}}\right)\left[\sqrt{1-\left(\frac{\varphi_{m}-\varphi_{s}}{\varphi_{m}}\right)^{2}}\right] \varphi_{s} \\
k=\frac{\varphi_{e f f}}{\varphi_{s}}=\frac{1}{1-c \varphi_{s}} w h e r e c=\frac{1-\varphi_{m}}{\varphi_{m}} \\
k=\frac{\varphi_{e f f}}{\varphi_{s}}=\frac{1}{\varphi_{s}}\left[1-\exp \left(-\frac{\varphi_{s}}{1-\left(\varphi_{s} / \varphi_{m}\right)}\right)\right]
\end{gathered}
$$

Equation (34) assumes the aggregation coefficient $k$ to be constant, independent of the volume fraction of the solvated nanoparticles. All other expressions (Equations (35)-(38)) follow the constraints that: $k \rightarrow 1$ when $\varphi_{s} \rightarrow 0$ and $k \rightarrow 1 / \varphi_{m}$ when $\varphi_{s} \rightarrow \varphi_{m}$. Equation (35) assumes a linear relationship between $k$ and $\varphi_{s}$. Equation (36) satisfies the additional constraint that $d k / d \varphi_{s} \rightarrow 0$ when $\varphi_{s} \rightarrow \varphi_{m}$ and it was successfully applied by Pal [49] in describing the aggregation of asphaltene solutions. The effective volume fraction $\varphi_{\text {eff }}$ defined by Equation (37), assuming no solvation of particles, was referred to as "rheological concentration" by Rutgers [50] in his paper on large micron-sized particulate suspensions. The effective volume fraction defined by Equation (38) in the absence of any solvation of particles has been successfully used to describe the shear modulus of suspensions of large micron-sized suspensions [51,52].

Figure 3 shows the plots of effective volume fraction $\varphi_{\text {eff }}$ versus volume fraction of un-aggregated solvated particles $\varphi_{s}$ generated from Equations (34) to (38). As can be seen, the effective volume fraction predicted by the equations falls well above the $\varphi_{\text {eff }}=\varphi_{s}$ line. In the presence of any aggregation of particles, it is expected that $\varphi_{\text {eff }}>\varphi_{s}$. The difference between $\varphi_{\text {eff }}$ and $\varphi_{s}$ increases with the increase in $\varphi_{s}$ due to growth of aggregates. At high values of $\varphi_{s}\left(\varphi_{s}>0.36\right)$, the predicted values of $\varphi_{\text {eff }}$ from different equations can be placed in the following order: Equation (38) > Equation (34) > Equation (36) $>$ Equation (35) > Equation (37) > no aggregation line. However, at low values of $\varphi_{s}\left(\varphi_{s}<0.36\right)$, Equation (34) predicts the highest value of $\varphi_{\text {eff }}$ and the order of prediction is as follows: Equation (34) $>$ Equation (36) $\approx$ Equation (38) > Equation (35) > Equation (37) > no aggregation line. 


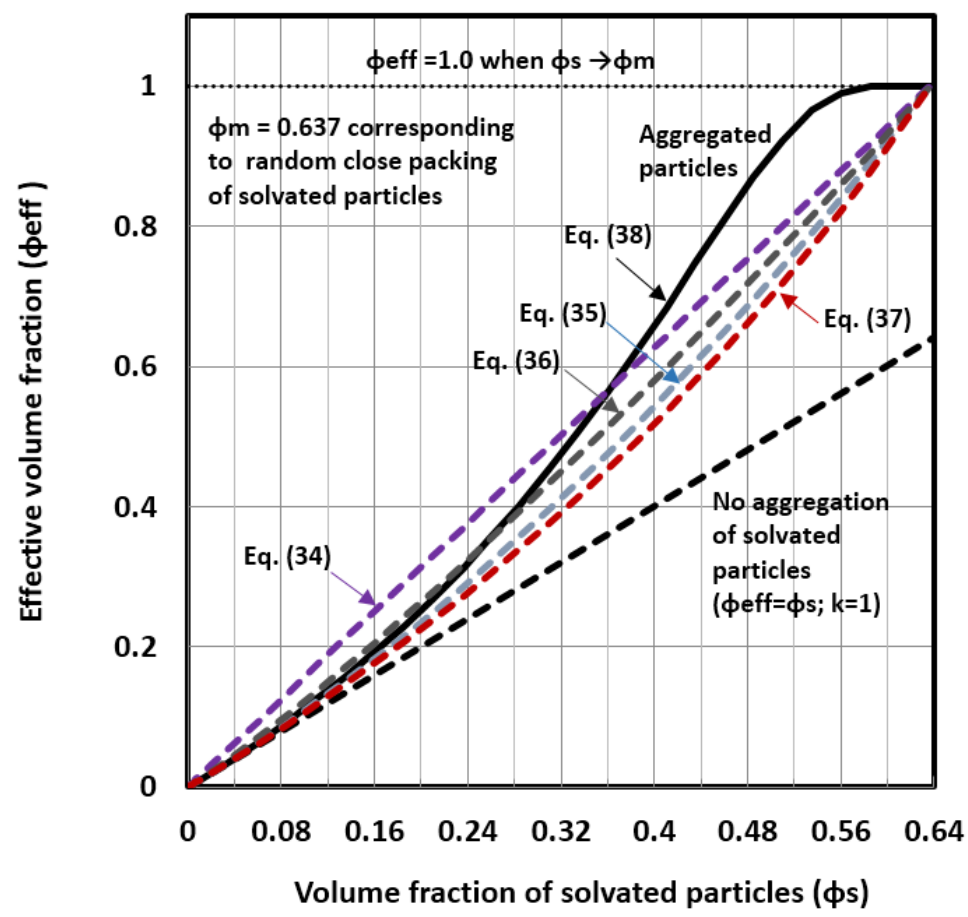

Figure 3. Effective volume fraction $\varphi_{\text {eff }}$ versus volume fraction of un-aggregated solvated particles $\varphi_{s}$ generated from Equations (34) to (38).

\section{Comparison of Model Predictions with Experimental Data and Discussion}

Four sets of experimental data on the viscosity of nanoemulsions and six sets of experimental data on the viscosity of nanosuspensions are considered to validate the model. The details of the various nanofluids considered in this work are given in Table 1 . In the case of the non-Newtonian shear-thinning nanofluids, only the low (zero) shear-rate viscosity data are considered.

Table 1. Details of the nanofluids considered in the present work.

\begin{tabular}{ccccc}
\hline $\begin{array}{c}\text { Set } \\
\text { No }\end{array}$ & $\begin{array}{c}\text { Type of } \\
\text { Nanofluid }\end{array}$ & $\begin{array}{c}\text { Type and Diameter of } \\
\text { un-Solvated Nanoparticles } \mathbf{( n m})\end{array}$ & $\begin{array}{c}\text { Temperature } \\
\left({ }^{\circ} \mathbf{C}\right)\end{array}$ & Reference \\
\hline 1 & nanoemulsion & oil nanodroplets; $205 \mathrm{~nm}$ & 20 & Van der Waarden [44] \\
2 & nanoemulsion & oil nanodroplets; $102 \mathrm{~nm}$ & 20 & Van der Waarden [44] \\
3 & nanoemulsion & oil nanodroplets; $58.5 \mathrm{~nm}$ & 20 & Van der Waarden [44] \\
4 & nanoemulsion & oil nanodroplets; $27.5 \mathrm{~nm}$ & 20 & Van der Waarden [44] \\
5 & nanosuspension & $\mathrm{Al}_{2} \mathrm{O}_{3} ; 36 \mathrm{~nm}$ & $22-25$ & Nguyen et al. $[14]$ \\
6 & nanosuspension & $\mathrm{Al}_{2} \mathrm{O}_{3} ; 47 \mathrm{~nm}$ & $22-25$ & Nguyen et al. [14] \\
7 & nanosuspension & $\mathrm{CuO} ; 29 \mathrm{~nm}_{25}$ & $22-25$ & Nguyen et al. [18] \\
8 & nanosuspension & Poly(styrene) latex; $146 \mathrm{~nm}$ & 20 & Weiss et al. [53] \\
9 & nanosuspension & Polymer; $56 \mathrm{~nm}$ & 20 & Jones et al. [54] \\
10 & nanosuspension & Silica; $50 \mathrm{~nm}$ & 20 & Jones et al. [55] \\
\hline
\end{tabular}

Figures 4 and 5 show the experimental data for nanofluids in terms of relative viscosity versus the actual volume fraction of nanoparticles without any consideration of solvation and aggregation of nanoparticles. Figure 4 shows four sets of relative viscosity data for oil-in-water nanoemulsions [44] with different droplet sizes. The droplet diameter varies from $205 \mathrm{~nm}$ (set 1) to $27.5 \mathrm{~nm}$ (set 4). With the decrease in the droplet diameter, the relative viscosity increases sharply at any given volume fraction of oil nanodroplets. Figure 5 shows six sets of data for nanosuspensions [14,18,53-55]. The type and size of nanoparticles vary from one set to another. Clearly a very wide variation in relative 
viscosity is observed at any given volume fraction of nanoparticles, depending on the size and type of nanoparticles.

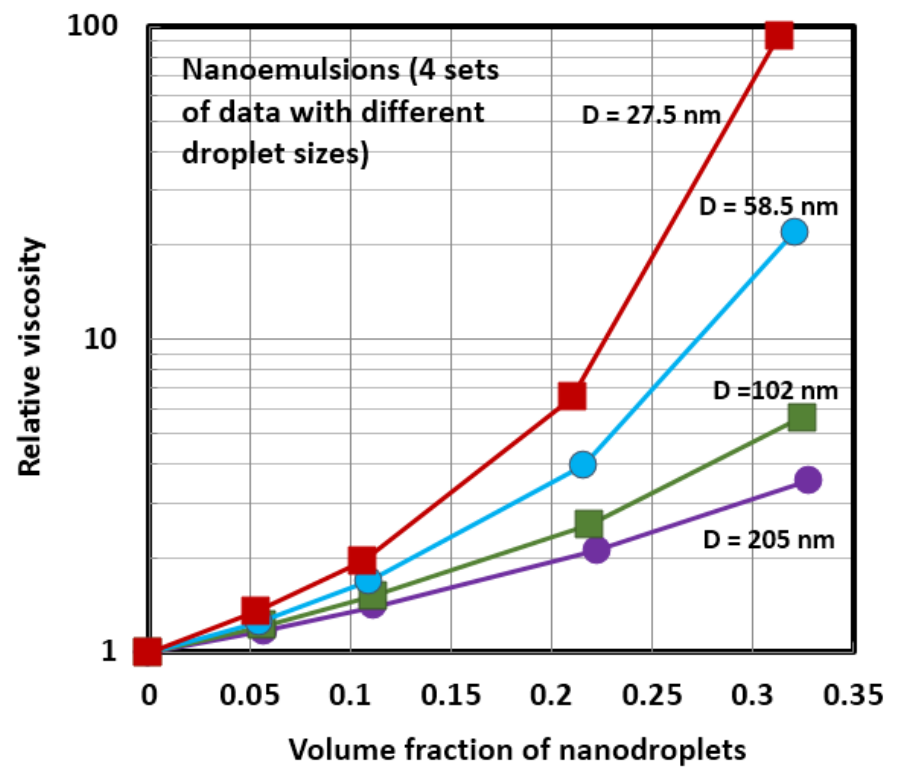

Figure 4. Experimental data for the viscosity of oil-in-water nanoemulsions of different droplet sizes.

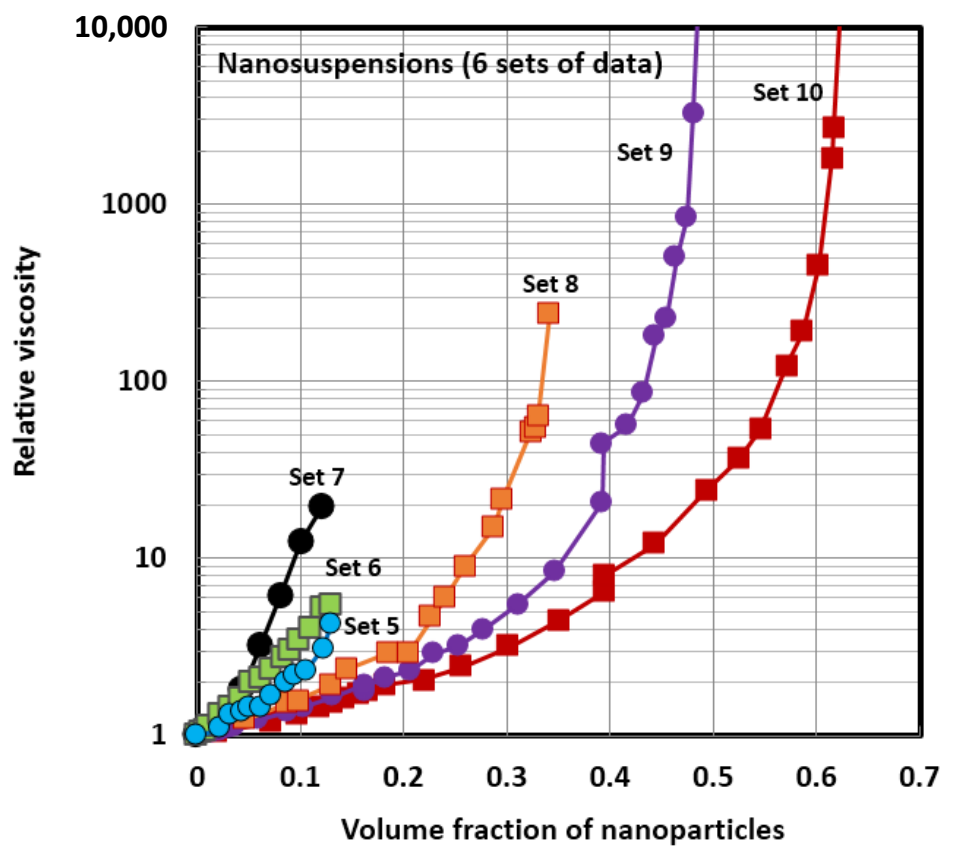

Figure 5. Six sets of experimental data for the viscosity of nanosuspensions.

The intrinsic viscosity of a nanofluid is estimated from the viscosity data of dilute nanofluid by plotting $1 / \eta_{r}$ versus $\varphi$, where $\varphi$ is the volume fraction of un-solvated nanoparticles. The slope of $1 / \eta_{r}$ versus $\varphi$ data in the limit of $\varphi \rightarrow 0$ is $-[\eta]$. Figure 6 shows the typical plot of $1 / \eta_{r}$ versus $\varphi$ for nanoemulsion with corresponding value of $[\eta]$. As expected, the plot of $1 / \eta_{r}$ versus $\varphi$ data is linear in the limit of $\varphi \rightarrow 0$. A similar behavior is observed (see Figure 7) in the case of nanosuspensions. From the intrinsic viscosity values, the solvation coefficient, the thickness of the solvation layer, and the volume fraction of solvated layer in a solvated droplet, are determined. The values of $[\eta], k_{s}, \delta$, and $\varphi_{S L}$ are summarized in Table 2. 


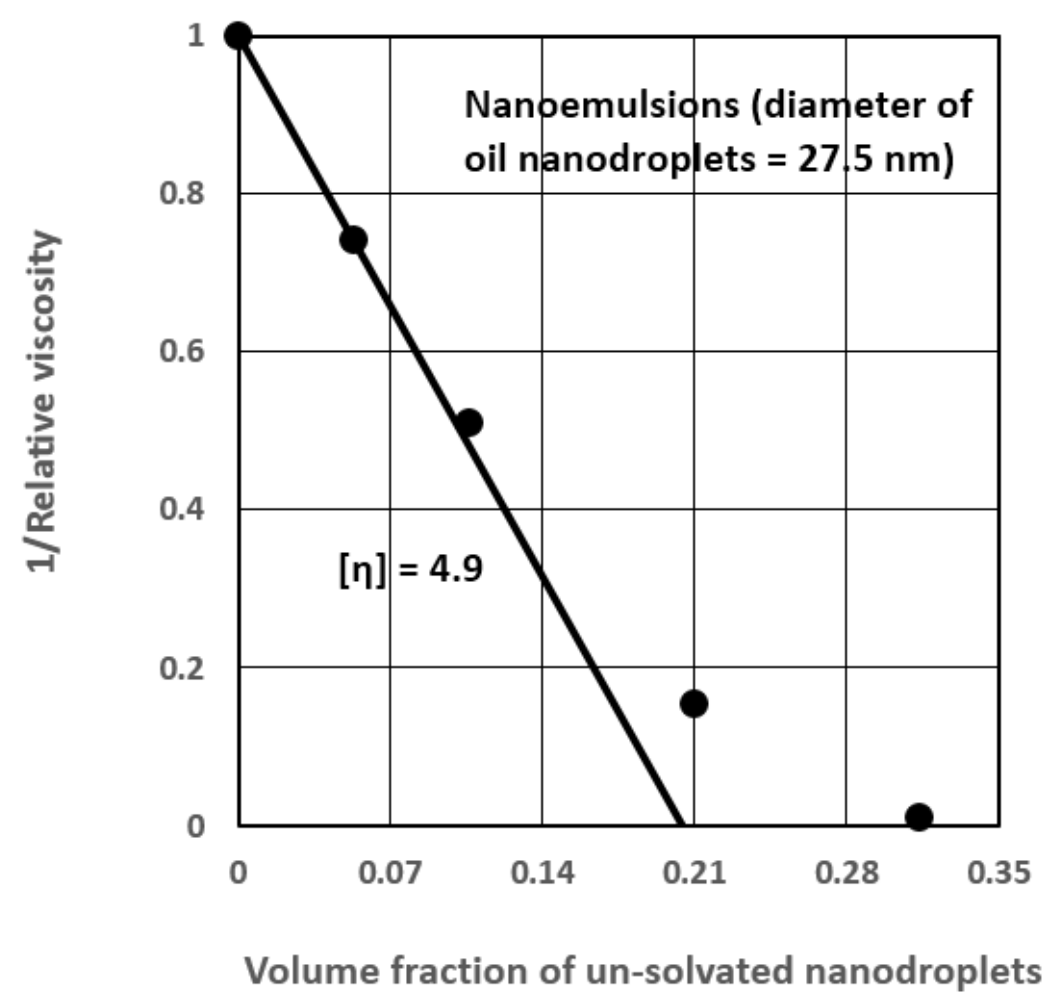

Figure 6. Estimation of intrinsic viscosity of nanoemulsion (set 4, see Table 2).

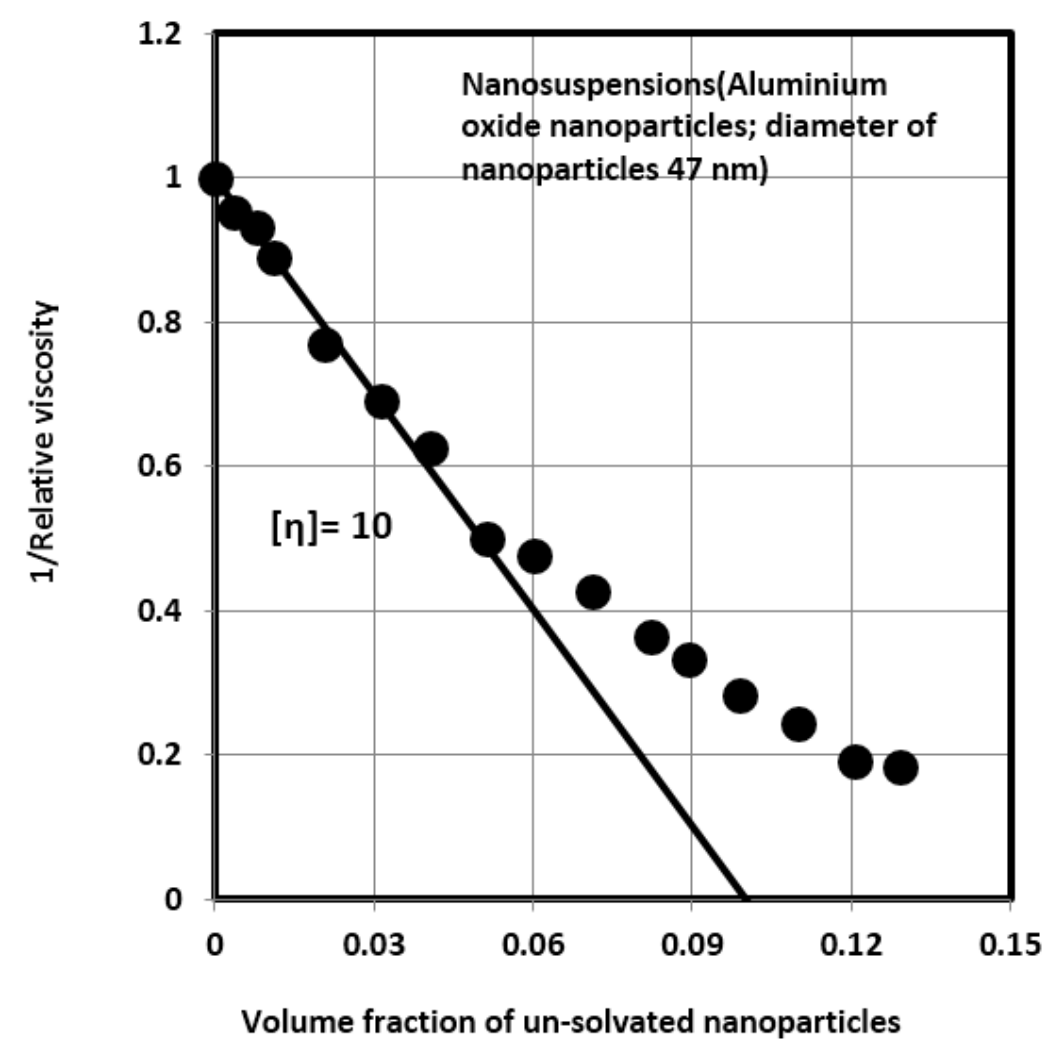

Figure 7. Estimation of intrinsic viscosity of nanosuspension (set 6, see Table 2). 
Table 2. Intrinsic viscosity, solvation coefficient, thickness of solvation layer, and $\varphi_{S L}$ of the nanofluids.

\begin{tabular}{cccccc}
\hline $\begin{array}{c}\text { Set } \\
\text { No }\end{array}$ & $\begin{array}{c}\text { Type of Nanofluid } \\
\text { and Diameter (nm) }\end{array}$ & $\begin{array}{c}\text { Intrinsic } \\
\text { Viscosity, }[\eta]\end{array}$ & $\begin{array}{c}\text { Solvation } \\
\text { Coefficient, } \mathbf{k}_{\mathbf{s}}\end{array}$ & $\begin{array}{c}\text { Thickness of Solvation } \\
\text { Nanolayer, } \delta \text { (nm) }\end{array}$ & $\begin{array}{c}\text { Volume Fraction of } \\
\text { Solvated Layer in the } \\
\text { Solvated Droplet, } \boldsymbol{\varphi}_{S L}\end{array}$ \\
\hline 1 & Nanoemulsion (205) & 2.65 & 1.077 & 2.58 & 0.072 \\
2 & Nanoemulsion (102) & 3.05 & 1.243 & 3.83 & 0.195 \\
3 & Nanoemulsion (58.5) & 3.8 & 1.555 & 4.64 & 0.357 \\
4 & Nanoemulsion (27.5) & 4.9 & 2.018 & 3.63 & 0.504 \\
5 & Nanosuspension (36) & 5.65 & 2.26 & 5.62 & 0.557 \\
6 & Nanosuspension (47) & 10 & 4.0 & 13.80 & 0.75 \\
7 & Nanosuspension (29) & 11 & 4.4 & 9.26 & 0.773 \\
8 & Nanosuspension (146) & 3.9 & 1.56 & 11.66 & 0.359 \\
9 & Nanosuspension (56) & 3.39 & 1.36 & 3.02 & 0.265 \\
10 & Nanosuspension (50) & 2.5 & 1.0 & $\approx 0$ & $\approx 0$ \\
\hline
\end{tabular}

\subsection{Scaling of Relative Viscosity of Nanoemulsions and Nanosuspensions}

The relative viscosity data of nanoemulsions shown in Figure 4 are re-plotted as $\eta_{r}$ versus $\varphi_{s}$, where $\varphi_{s}$ is the volume fraction of solvated nanoparticles/nanodroplets given as: $\varphi_{s}=k_{s} \varphi$. Figure 8 shows the four sets of data for nanoemulsions. The scaling of relative viscosity of nanoemulsions on a $\varphi_{s}$ basis is remarkable in that the data for different nanoemulsions covering a wide range of nanodroplet sizes (see Figure 4) all fall on the same curve. Furthermore the data can be described reasonably well by the modified Oldroyd model, Equation (25), in conjunction with the $\varphi_{\text {eff }}$ relation, Equation (36), using a $\varphi_{m}$ of 0.637 . This $\varphi_{m}$ value corresponds to random close packing of uniform spheres. As the nanoemulsion droplets were spherical and nearly uniform in size [44], it is justified to use a $\varphi_{m}$ value of 0.637 . The other $\varphi_{e f f}$ relations (Equations (34), (35), (37) and (38)) were not as good as Equation (36) in describing the experimental data.

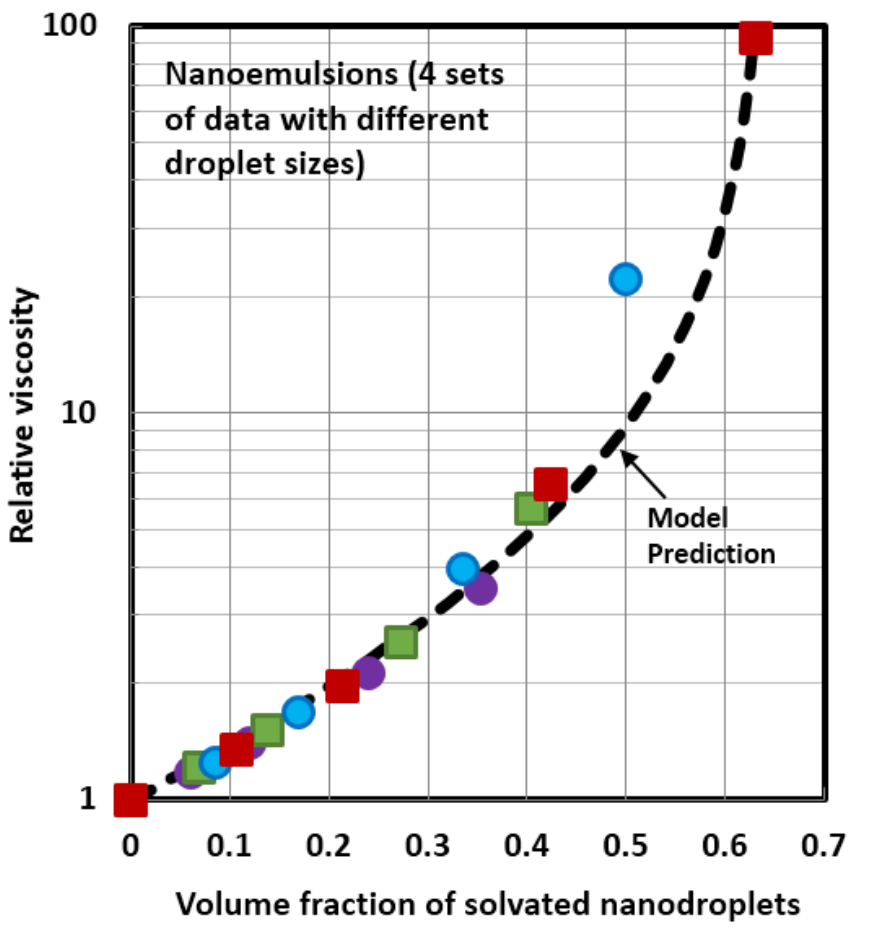

Figure 8. Scaling of relative viscosity of oil-in-water nanoemulsions of different droplet sizes.

The six sets of relative viscosity data of nanosuspensions shown in Figure 5 are re-plotted as $\eta_{r}$ versus $\varphi_{s}$ in Figure 9. The scaling of relative viscosity of nanosuspensions on a $\varphi_{s}$ basis is also remarkable if we compare Figures 5 and 9 . The wide range of nanosuspension data shown in Figure 5 
is brought close to each other when plotted on a $\varphi_{s}$ basis in Figure 9. Using a single $\varphi_{m}$ value of 0.637 (random close packing of uniform spheres), the modified Oldroyd model proposed in this work (Equation (25) in conjunction with $\varphi_{\text {eff }}$ relation Equation (36)) describes the data reasonably well. The agreement between the model prediction and experimental data could be improved further by allowing $\varphi_{m}$ to vary somewhat from one set of data to another. It should be noted that $\varphi_{m}$ is sensitive to shape and size distribution of particles. In the case of nanosuspensions, the nanoparticles are not exactly spherical and uniform in size. The shape and size distribution of nanoparticles are in all likelihood not the same in different sets of nanosuspension data considered here. Figure 10 shows the improved agreement between the data and the model predictions when the $\varphi_{m}$ is allowed to vary from one set to another. The relative viscosity in Figure 10 is plotted against the effective volume fraction $\varphi_{e f f}$. The $\varphi_{m}$ variation from one set to another is embedded in $\varphi_{\text {eff }}$ (see Equation (36)). The $\varphi_{m}$ values range from 0.54 to 0.74 (set 5: 0.58 , set 6: 0.74 , set 7: 0.58 , set 8: 0.54 ; set 9: 0.637 , set 10: 0.615 ). The variation of $\varphi_{m}$ from one set to another could be due to different structures of packing of particles in the clusters. For example, it is well known that $\varphi_{m}=0.52$ for simple cubic-packing of spheres; $\varphi_{m}=0.58$ for colloidal glassy state; $\varphi_{m}=0.637$ for random close packing of spheres; $\varphi_{m}=0.68$ for body-centered cubic packing of spheres; and $\varphi_{m}=0.74$ for hexagonal close packing of spheres.

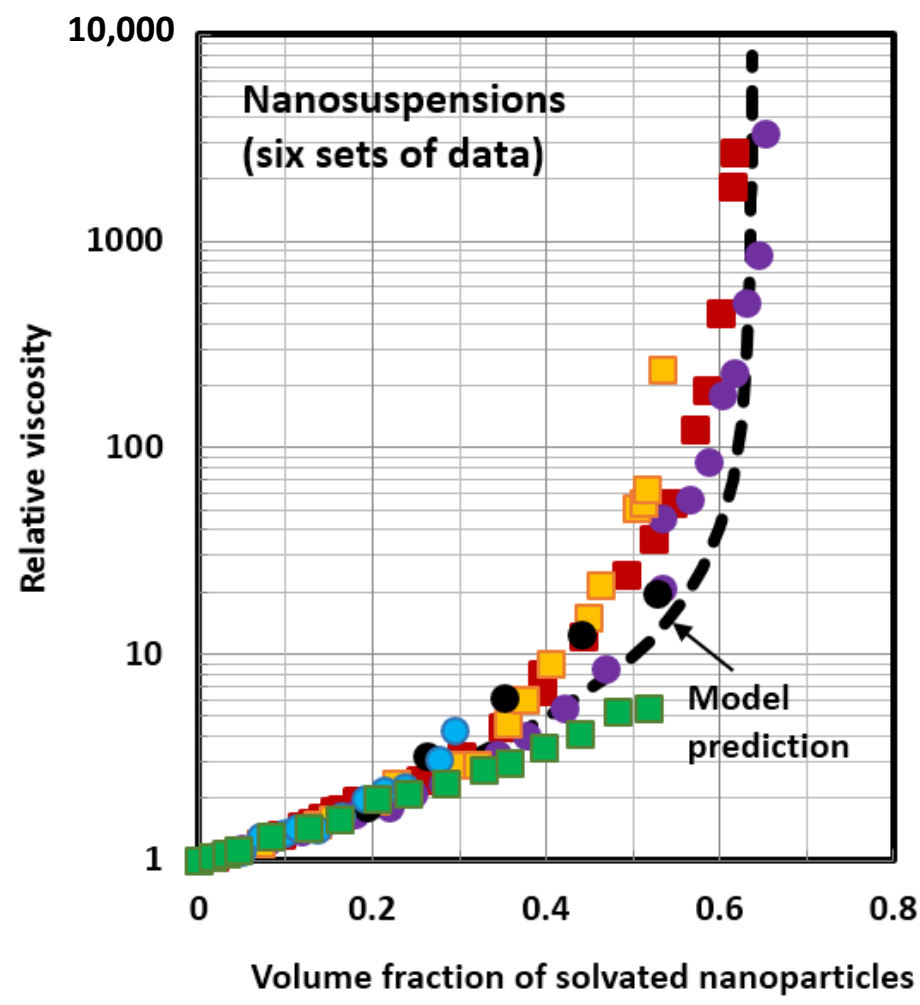

Figure 9. Scaling of relative viscosity of nanosuspensions.

\subsection{Influence of Viscosity Ratio on the Relative Viscosity of Nanoemulsions}

One important difference between nanoemulsions and nanosuspensions is the fluidic nature of the dispersed-phase. In the case of nanoemulsions, the dispersed-phase consists of fluidic nanodroplets whereas the dispersed-phase of nanosuspensions consists of solid and rigid nanoparticles. Only in the limit of viscosity ratio $\lambda \rightarrow \infty$, the nanodroplets could be considered as solid and rigid nanoparticles. Thus, it is important to consider the effect of the viscosity ratio $\lambda$ on the relative viscosity of nanofluids. Figure 11 shows the relative viscosity versus viscosity ratio $\lambda$ plots for nanoemulsions for different values of the effective volume fraction $\varphi_{\text {eff }}$. The plots are generated using the model Equation (25). At any given $\varphi_{e f f}$, the plot of relative viscosity exhibits three distinct regions: (a) low-viscosity lower 
plateau region corresponding to $\lambda \leqslant 0.01$ where the relative viscosity of the nanofluid is the lowest. In this region, the nanofluid consists of nanobubbles as the dispersed-phase; (b) intermediate region corresponding to $0.01 \leqslant \lambda \leqslant 1000$ where the relative viscosity of a nanofluid rises rapidly with the increase in the viscosity ratio. The nanoemulsions fall into this region; and (c) high-viscosity upper plateau region corresponding to $\lambda \geqslant 1000$ where the relative viscosity of the nanofluid is the highest. In this region, the nanofluid is a nanosuspension consisting of solid and rigid nanoparticles as the dispersed-phase. Finally note that the relative viscosity versus viscosity ratio plot shifts upward with the increase in the effective volume fraction of the dispersed-phase indicating an increase in the relative viscosity with the increase in the effective volume fraction of nanoparticles.

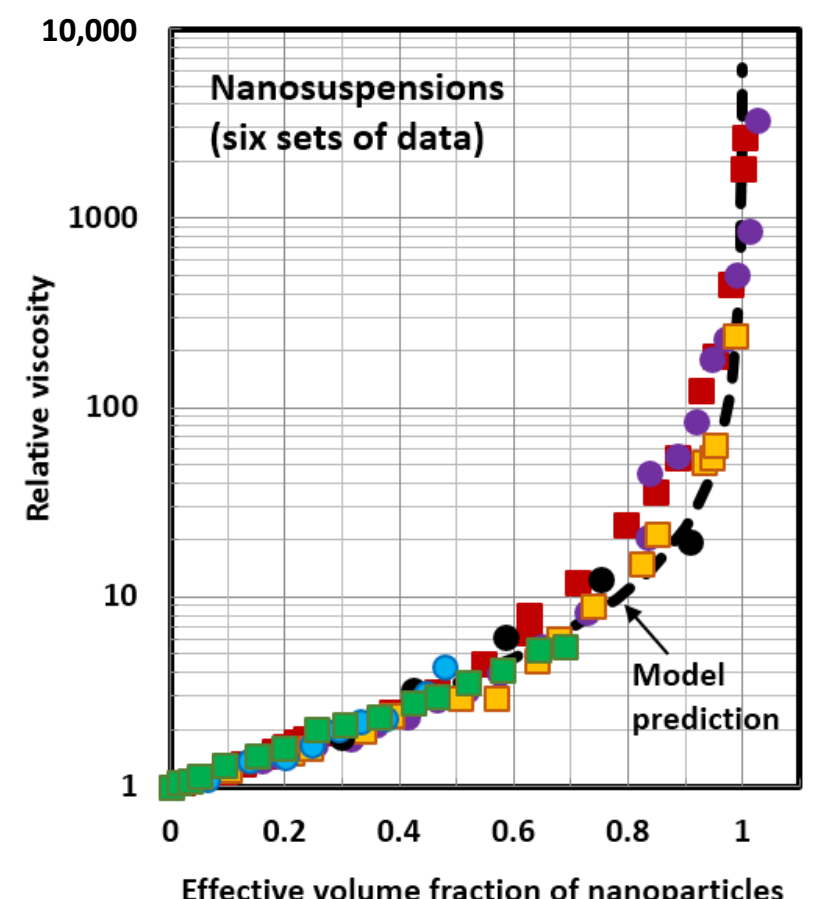

Figure 10. Comparison of model prediction with six sets of experimental data for nanosuspensions.

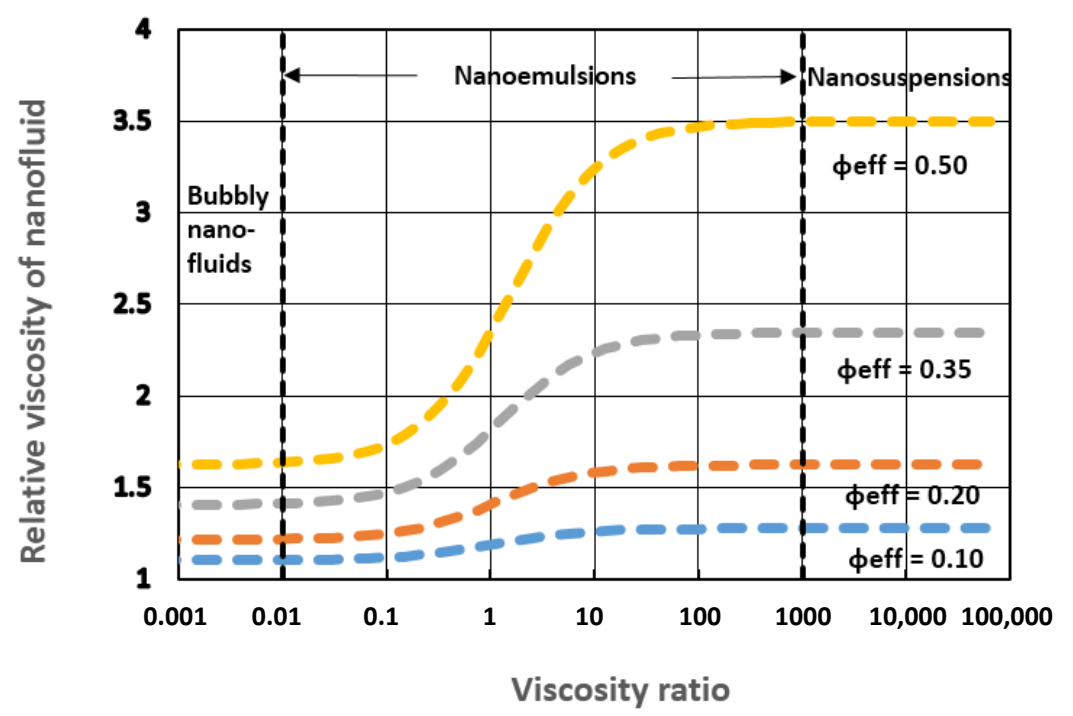

Figure 11. Influence of viscosity ratio on the relative viscosity of nanofluids. 


\section{Conclusions}

Based on the analysis and discussion presented in this article, the following conclusions can be made:

- The relative viscosity of a nanofluid is strongly affected by factors such as solvation and aggregation of nanoparticles/nanodroplets. In the case of nanoemulsions, the additional factor affecting the viscosity is the viscosity ratio (ratio of nanodroplet viscosity to base fluid viscosity).

- The relative viscosity data for different nanofluids can be collapsed together on to a single unique curve if the data are plotted as relative viscosity versus volume fraction of solvated nanoparticles/nanodroplets. This scaling approach is valid for both nanosuspensions and nanoemulsions.

- A new modified version of the Oldroyd model describes the relative viscosity versus particulate concentration behavior of nanoemulsions and nanosuspensions reasonably well. The model takes into consideration the influences of the viscosity ratio, solvation and aggregation of nanoparticles/nanodroplets.

- The influence of the viscosity ratio on the relative viscosity of nanoemulsions is important. The relative viscosity of a nanoemulsion increases substantially with the increase in the viscosity ratio.

- Systematic experimental studies on the effect of viscosity ratio on viscous behavior of nanoemulsions are lacking. More work needs to be done in this area.

Acknowledgments: Financial support from the Natural Sciences and Engineering Research Council of Canada (NSERC) is appreciated.

Conflicts of Interest: The author declares no conflict of interest.

\section{References}

1. Das, S.K.; Choi, S.U.S.; Yu, W.; Pradeep, T. Nanofluids; Wiley: New York, NY, USA, 2008.

2. Patel, V.R.; Agrawal, Y.K. Nanosuspension: An approach to enhance solubility of drugs. J. Adv. Pharm. Technol. Res. 2011, 2, 81-87. [PubMed]

3. Wang, Y.; Zheng, Y.; Zhang, L.; Wang, Q.; Zhang, D. Stability of nanosuspensions in drug delivery. J. Control. Release 2013, 172, 1126-1141. [CrossRef] [PubMed]

4. Lakshmi, P.; Kumar, G.A. Nanosuspension technology: A review. Int. J. Pharm. Pharmaceutical. Sci. 2010, 2, $35-40$.

5. Jamshidi, N.; Farhadi, M.; Ganji, D.D.; Sedighi, K. Experimental investigation on the viscosity of nanofluids. Int. J. Eng. 2012, 25, 201-209. [CrossRef]

6. Mahbubul, I.M.; Saidur, R.; Amalina, M.A. Latest developments on the viscosity of nanofluids. Int. J. Heat Mass Transf. 2012, 55, 874-885. [CrossRef]

7. Tiwari, A.K.; Ghosh, P.; Sarkar, J. Investigation of thermal conductivity and viscosity of nanofluids. J. Environ. Res. Dev. 2012, 7, 768-777.

8. Kumar, P.C.M.; Kumar, J.; Suresh, S. Review of nanofluid theoretical viscosity models. Int. J. Eng. Innov. Res. 2012, 1, 182-188.

9. Duan, F.; Kwek, D.; Crivoi, A. Viscosity affected by nanoparticle aggregation in $\mathrm{Al}_{2} \mathrm{O}_{3}$-water nanofluids. Nanoscale Res. Lett. 2011, 6, 248. [CrossRef] [PubMed]

10. Xu, J.; Yang, B.; Hammouda, B. Thermal conductivity and viscosity of self-assembled alcohol/polyalphaolefin nanoemulsion fluids. Nanoscale Res. Lett. 2011, 6. [CrossRef] [PubMed]

11. Hosseini, S.S.; Shahrjerdi, A.; Vazifeshenas, Y. A review of relations for physical properties of nanofluids. Australian J. Basic Appl. Sci. 2011, 5, 417-435.

12. Lee, S.W.; Park, S.D.; Kang, S.; Bang, I.C.; Kim, J.H. Investigation of viscosity and thermal conductivity of $\mathrm{SiC}$ nanofluids for heat transfer applications. Int. J. Heat Mass Transf. 2011, 54, 433-438. [CrossRef]

13. Namburu, P.K.; Kulkarni, D.P.; Misra, D.; Das, D.K. Viscosity of copper oxide nanoparticles dispersed in ethylene glycol and water mixture. Exp. Therm. Fluid Sci. 2007, 32, 397-402. [CrossRef] 
14. Nguyen, C.T.; Desgranges, F.; Galanis, N.; Roy, G.; Mare, T.; Boucher, S.; Angue Mintsa, H. Viscosity data for $\mathrm{Al}_{2} \mathrm{O}_{3}$-Water nanofluid-Hysteresis: Is heat transfer enhancement using nanofluids reliable? Int. J. Thermal Sci. 2008, 47, 103-111. [CrossRef]

15. Wang, X.Q.; Mujumdar, A.S. Heat transfer characteristics of nanofluids: A review. Int. J. Ther. Sci. 2007, 46, 1-19. [CrossRef]

16. Wang, X.Q.; Mujumdar, A.S. A review of nanofluids. Braz. J. Chem. Eng. 2008, 25, 613-630.

17. Chen, H.; Ding, Y.; He, T.; Tan, C. Rheological behavior of ethylene glycol based titania nanofluids. Chem. Phys. Lett. 2007, 444, 333-337. [CrossRef]

18. Nguyen, C.T.; Desgranges, F.; Roy, G.; Galanis, N.; Mare, T.; Boucher, S.; Angue Mintsa, H. Temperature and particle-size dependent viscosity data for water-based nanofluids-Hysteresis phenomenon. Int. J. Heat Fluid Flow 2007, 28, 1492-1506. [CrossRef]

19. Pal, R. New models for the viscosity of nanofluids. J. Nanofluids 2014, 3, 260-266. [CrossRef]

20. Chiesa, M.; Garg, J.; Kang, Y.T.; Chen, G. Thermal conductivity and viscosity of water-in-oil nanoemulsions. Coll. Surfaces A Physicochem. Eng. Asp. 2008, 326, 67-72. [CrossRef]

21. Saarinen, S.; Puupponen, S.; Merilainen, A.; Joneidi, A.; Seppala, A.; Saari, K.; Ala-Nissila, T. Turbulent heat transfer characteristics in a circular tube and thermal properties of $\mathrm{N}$-decane-in-water nanoemulsion fluids and micelles-in-water fluids. Int. J. Heat Mass Transf. 2015, 81, 246-251. [CrossRef]

22. Yu, L.; Chao, L.; Jian, X.; Hao, J.; Sun, D. Highly stable concentrated nanoemulsions by the phase inversion composition method at elevated temperature. Langmuir 2012, 28, 14547-14552. [CrossRef] [PubMed]

23. Yang, B.; Han, Z. A new type of nanoengineered heat transfer fluids: Nanoemulsion fluids. In Proceedings of the ASME 2006 International Mechanical Engineering Congress and Exposition, Chicago, IL, USA, 5-10 November 2006; pp. 333-336.

24. Yang, B.; Han, Z.H. Thermal conductivity enhancement in water-in-FC72 nanoemulsion fluids. Appl. Phys. Lett. 2006, 88, 261914. [CrossRef]

25. Han, Z.H.; Yang, B. Therophysical characteristics of water-in-FC72 nanoemulsion fluids. Appl. Phys. Lett. 2009, 92, 013118. [CrossRef]

26. Xu, J.; Hammouda, B.; Cao, F.; Yang, B. Experimental study of thermophysical properties and nanostructure of self-assembled water/polyalphaolefin nanoemulsion fluids. Adv. Mech. Eng. 2015, 7, 1-8. [CrossRef]

27. Yang, B.; Han, Z.; Cao, F.; Xu, J.; Ahuja, H. Thermophysical properties of nanostructured heat transfer fluids. In Proceedings of the Second International Energy 2030 Conference, Abu Dhabi, UAE, 4-5 November 2008.

28. Pal, R. Rheology of Particulate Dispersions and Composites; CRC Press: Boca Raton, FL, USA, 2007.

29. Pal, R. Evaluation of theoretical viscosity models for concentrated emulsions at low capillary numbers. Chem. Eng. J. 2001, 81, 15-21. [CrossRef]

30. Einstein, A. Eine neue Bestimmung der Molekuldimension. Ann. Phys. (Leipzig) 1906, 19, 289-306. [CrossRef]

31. Einstein, A. Berichtigung zu meiner Arbeit: Eine neue Bestimmung der Molekuldimension. Ann. Phys. (Leipzig) 1911, 34, 591-592. [CrossRef]

32. Pal, R. Rheology of emulsions containing polymeric liquids. In Encyclopedia of Emulsion Technology; Chapter 3; Becher, P., Ed.; Dekker: New York, NY, USA, 1996; Volume 4.

33. Taylor, G.I. The viscosity of a fluid containing small drops of another liquid. Proc. R. Soc. Lond. A 1932, 138, 41-48. [CrossRef]

34. Pal, R. Rheology of simple and multiple emulsions. Curr. Opin. Coll. Interface Sci. 2011, 16, 41-60. [CrossRef]

35. Saito, N. Concentration dependence of the viscosity of high polymer solutions. J. Phys. Soc. Jpn. 1950, 5, 4-8. [CrossRef]

36. Batchelor, G.K.; Green, J.T. The determination of the bulk stress in a suspension of spherical particles to the order c c $^{2}$ J. Fluid Mech. 1972, 56, 401-427. [CrossRef]

37. Batchelor, G.K. Effect of Brownian motion on bulk stress in a suspension of spherical particles. J. Fluid Mech. 1977, 83, 97-117. [CrossRef]

38. Roscoe, R. The viscosity of suspensions of rigid spheres. Br. J. Appl. Phys. 1952, 3, 267-269. [CrossRef]

39. Brinkman, H.C. The viscosity of concentrated suspensions and solutions. J. Chem. Phys. 1952, 20, 571-581. [CrossRef]

40. Mooney, M. The viscosity of a concentrated suspensions of spherical particles. J. Coll. Sci. 1951, 6, 162-170. [CrossRef] 
41. Krieger, I.M.; Dougherty, T.J. Mechanism for non-Newtonian flow in suspensions of rigid particles. Trans. Soc. Rheol. 1959, 3, 137-152. [CrossRef]

42. Oldroyd, J.G. The elastic and viscous properties of emulsions and suspensions. Proc. R. Soc. Lond. A 1953, 218, 122-132. [CrossRef]

43. Pal, R. Novel viscosity equations for emulsions of two immiscible liquids. J. Rheol. 2001, 45, 509-520. [CrossRef]

44. Van der Waarden, M. Viscosity and electroviscous effect of emulsions. J. Coll. Sci. 1954, 9, 215-222. [CrossRef]

45. He, L.; Hu, Y.; Wang, M.; Yin, Y. Determination of solvation layer thickness by a magnetophotonic approach. ACS Nano 2012, 6, 4196-4202. [CrossRef] [PubMed]

46. McClements, D.J. Edible nanoemulsions: Fabrication, properties, and functional performance. Soft Matter 2011, 7, 2297-2316. [CrossRef]

47. Gao, J.W.; Zheng, R.T.; Ohtani, H.; Zhu, D.S.; Chen, G. Experimental investigation of heat conduction mechanisms in nanofluids. Clue on clustering. Nano Lett. 2009, 9, 4128-4132. [CrossRef] [PubMed]

48. Karthikeyan, N.R.; Philip, J.; Raj, B. Effect of clustering on the thermal conductivity of nanofluids. Mater. Chem. Phys. 2008, 109, 50-55. [CrossRef]

49. Pal, R. A new model for the viscosity of asphaltene solutions. Can. J. Chem. Eng. 2015, 93, 747-755. [CrossRef]

50. Rutgers, R. Relative viscosity and concentration. Rheol. Acta 1962, 2, 305-348. [CrossRef]

51. Pal, R. A new linear viscoelastic model for emulsions and suspensions. Poly. Eng. Sci. 2008, 48, 1250-1253. [CrossRef]

52. Lewis, T.; Nielsen, L. Dynamic mechanical properties of particulate-filled composites. J. Appl. Polym. Sci. 1970, 14, 1449-1471. [CrossRef]

53. Weiss, A.; Dingenouts, N.; Ballaquff, M.; Senf, H.; Richtering, W. Comparison of the effective radius of sterically stabilized latex particles determined by small angle X-ray scattering and by zero shear viscosity. Langmuir 1998, 14, 5083-5087. [CrossRef]

54. Jones, A.A.R.; Leary, B.; Boger, D.V. The rheology of a sterically stabilized suspension at high concentration. J. Coll. Interface Sci. 1992, 150, 84-96. [CrossRef]

55. Jones, A.A.R.; Leary, B.; Boger, D.V. The rheology of a concentrated colloidal suspension of hard spheres. J. Coll. Interface Sci. 1991, 147, 479-495. [CrossRef]

(C) 2016 by the author; licensee MDPI, Basel, Switzerland. This article is an open access article distributed under the terms and conditions of the Creative Commons Attribution (CC-BY) license (http://creativecommons.org/licenses/by/4.0/). 